\title{
NOTICE OF ORGANIZATIONAL NAME CHANGE
}

At the 1982 meetings, the decision was made to change the name of the National Conference on the Use of On-Line Computers in Psychology to the Society for Computers in Psychology. The selection of the new name resulted after a review and redefinition of the purpose of the organization, and a subsequent consideration of a number of titles submitted by members of the conference. 